\title{
Editorial Note: At the Heart of Body Politics
}

\author{
WENDY HARCOURT
}

As I write this I have just received an Internet rallying call for support by Nawal el Saadaw, the Egyptian writer, feminist and novelist, asking for international support against her impending trial. She faces divorce and incarceration for stating in a newspaper interview that the veiling of women is against the true spirit of Islam and correct interpretation of the Koranic text.

It is an urgent testimony to the ongoing battle against violence against women (VAW) and an example of the sophisticated outreach of the international women's movement in its resistance to the multiple forms of violence women encounter every day.

This issue of development closely follows the previous theme of women's rights and child rights (vol. 44.2) to look at VAW and the culture of masculinity. The issue aims to map out the state of today's 'body politics' - the political defence of women's freedom and right to bodily integrity, autonomy and security. As the international call of Nawal el Saadaw shows, women's groups are engaging in complex multilevel strategies of politics to negotiate gender, economic and social justice as part of local and global process. The articles in this issue show how the fight to end VAW is at the heart of body politics and the first entry point for women's economic, social and political rights.

The fight against violence in women's lives is one of the successes in the last two decades of the women's movement. It is not, sadly, that VAW has stopped, but it is now fully visible and its eradication is part of the global development agenda. Domestic violence, rape in war, sexual harassment, female genital mutilation, suttee, female infanticide, neglect and mistreatment of old women, sex trafficking, incarceration, are no longer seen as 'cultural', 'unspeakable', 'private', but are linked integrally to material expressions of community and public politics. VAW is now recognized as one of the most visible practices of discrimination against women that permeates all forms of political, economic, social and cultural relationships. 
Coming from the realities of women's lives around the world, the national and international mechanisms of the international women's movement have joined with governments and the United Nations to highlight VAW as a major impediment to women's rights and well-being. Major international development events such as, for example, the Vienna Conference on Human Rights, the Cairo International Conference on Population and Development, the Beijing World Conference on Women and the programmes of the World Health Organization have placed VAW as a major development issue. Such a political shift has been achieved through tireless lobbying and campaigning. It has not been an easy fight, and as the articles in this issue show it continues to be fraught with contradictions and tensions: two steps forward and one step back.

To take one example, in 1984 when female genital mutilation was first put on the international agenda it was almost immediately taken off again as an untouchable cultural issue. It was seen as too shocking, too private and too difficult to discuss openly. Now, in 2001, African women's groups can speak about the end of the practice in many communities with international testimonies that illustrate how damaging cultural and social customs can change with the knowledge and support of the international women's movement.

Nevertheless, female genital mutilation, like many other concerns that this issue speaks about, can still be taken out of context and used to objectify African customs as barbaric and by implication African women and Africa itself. There is still the danger of objectifying women as the victims, in need of outside intervention, rather than as the subjects of their own and their community's development.

I witnessed a recent testimony in the Roman Parliament where, despite the deeply moving and profound speeches of the women from The Gambia, Egypt, Tanzania and Sudan about their success in eradicating female genital mutilation among local communities, the Italian media picked up only the disturbing slides of mutilated vaginas. These images, introduced by a male medical doctor, totally silenced the voices of the women and made the good will and donations of the Italian audience.

The meeting forcibly reminded me of the problems of bringing to the international arena these issues. I felt extremely uncomfortable with the almost pornographic media interest in these images. Strategies that pander to a media that looks to shock, stereotype and objectify sexuality are not appropriate. It is important to maintain the dignity, security and well-being of women who have survived violence in their lives rather than to expose in a raw and crude way violated bodies. The backlash, the fear and resulting repression in some societies, for example the Egyptian Mufti trying to silence Nawal el Saadaw, urges even more care not to scandalize and to confront seriously and humanely all forms of VAW.

Most of all it must be recognized that the violence runs deep. VAW may have economic, legal and social implications but ending the practice demands psychological, sociological and cultural shifts that reach way beyond the usual discourse of development.

Also of profound importance are the different responses of men and women. Whereas many women immediately respond to the need to engage in body politics as part of the development agenda because of their own experience, or fear of violence, in contrast many men see VAW as outside their own experience, and therefore inappropriate and unrelated to economic and social development issues. VAW can be left to the domain of the nonpublic, or perhaps the sacred, certainly it is not the stuff of 'real' politics. Some women too encourage this response of men's non-responsibility by rigidly claiming the need for women only strategies to combat violence.

Strategies that encourage men to see VAW as being of critical concern for development is the second major theme of this issue. It seems new terrain for many, often having to go deep into the culture of masculinity, the identity of the macho and the patriarch, in ways reminiscent of the 1960s and 1970s identity politics of the women's movement. To break through the multiple levels of structural violence means to bite deep into many men's often unacknowledged experience of their own subjectivity. But given the widespread level of VAW, this is a necessary barrier to break. It is very 
encouraging to see the awakening of responsibility among the different men's groups contributing to these pages.

This journal issue has been a very important one for me. Ending VAW has been a personal struggle for many years. I have a renewed sense of hope that so many women and men wanted to share their stories with Development readers. The articles brim with a depth of experience and sophistication in analysis and approach that 20 years ago would not have been possible. From the knowledge and personal commitment shown in the Upfront overviews of Lenore Manderson and Michael Kaufman, both leaders in the field, to the resource list of material on VAW and men's movements that aim to stop VAW, this issue stands out for its richness of experience, commitment and honesty. The many innovative strategies to counter VAW - in the home, in the community, in war - through practical and ideological strategies are detailed with urgency and vision.

The two themes of the issue - building on successful wide reaching strategies against VAW and how to change the culture of masculinity to stop violence - are interwoven throughout. In the stories of how communities have in often very courageous ways confronted violence and brought about change locally and globally, the journal issue highlights some uncomfortable questions about the perpetuation of unacceptable levels of gender violence and exploitation. What are the economic and social conditions that are perpetuating and even increasing the level of VAW in poor homes and communities? How can campaigns involve men in the fight against gender violence when the global market pushes consumerism based on universal stereotypes of violent men and passive women? What are the contradictions in using the World Wide Web as a political medium to counter violence when pornographic sites dominate the Web's traffic? Why, if a majority of men continue to seek out prostitutes, does society legally create conditions that place both the sex workers and their clients in conditions that can lead to violence and death? How is it possible to avoid using the media to sensationalize VAW in ways that detract from the honest work of many women's and also men's groups to bring about real change in the community? How can local NGOs work together with national governments on gender violence when the economic and social enabling environment is preventing the necessary retraining and services of medical and other personnel?

These and many other questions are raised in order to galvanize the readers of Development into recognizing how the struggle to end VAW is fundamental to the global development agenda. I also hope, as Lenore Manderson suggests, that the journal issue belongs to the long ripples of change that lead to social justice.

Development is abstracted in Cab Abstracts, Communication Abstracts, Environmental Abstracts, GEOBASE, Geo Abstracts: Human Geography, HRI Reporter, International Development Abstracts, International Labour Documentation, International Political Science Abstracts, Social Services Abstracts, Sociofile and Sociological Abstracts; and is indexed in Worldwide Political Science Abstracts, Econlit, Environmental Abstracts, International Bibliography of the Social Sciences, Journal of Economic Literature, OCLC Public Affairs Information Service. 